\title{
Physiological and Notational Comparison of New and Old Scoring Systems of Singles Matches in Men's Badminton 新、舊制羽球男子單打比賽的生理與内容分析參數之比較
}

\author{
Hsin-Lian CHEN Chang-Jun WU Trevor C. CHEN \\ Department of Physical Education, National Chiayi University \\ Chiayi County, TAIWAN
}

陳信良吳稩潤陳忠慶

台灣嘉義縣國立嘉義大學體育系

\begin{abstract}
This study compared the physiological responses and shot selection preferences of male singles players between the new (rally-point) and old (scoring-by-service) scoring systems. Ten male athletes each played two matches against the same opponent on different days using the lottery method. Matches were notated using a systematic observation instrument, and physiological data were measured using heart rate (HR), ratings of perceived exertion (RPE) and blood lactate levels (LA). Results showed no differences in peak HR, RPE or LA responses between the two systems. However, players spent more time at an $\mathrm{HR}$ greater than $90 \% \mathrm{HR}_{\text {peak }}$ under the old system $(63 \%)$ than under the new system $(54 \%)$. Notational analysis demonstrated a significant decrease in total match playing time (PT: $29 \mathrm{~min})$, work time $(10 \mathrm{~min})$, work density (0.57), rest time (18 min), effective playing time (36\%), number of rallies (203) and serves (35) under the new system as compared to the old system (e.g. PT: $42 \mathrm{~min}$ ). No significant differences were noted between the two systems for number of shots, rally time, stroke time, frequency distribution of shot selection and positions during the matches, and for shot methods on the last shot of each rally. These findings suggest that the new system can significantly shorten PT compared to the old system, and that physiological responses, shot selection and positions do not affect between the systems. Meanwhile, the greater proportion of time spent at higher HR intensities under the old system may be attributed to the longer playing time with the opponent.
\end{abstract}

Keywords: rally-point scoring system, scoring-by-service scoring system, shuttlecock, peak heart rate ( $\mathrm{HR}_{\text {peak }}$, blood lactate (LA).

摘要

本研究目的, 針對「新 (落地得分)、舊制 (發球得分)羽球單打比賽時之生理反應和擊球方式」做比較。以羽球正式比賽 抽籤方式讓10位大學男子甲組羽球選手, 決定其各二場新、舊制羽球單打比賽同一位對手之方式。以高速攝影機拍攝每場比賽 做為系統性觀察法之內容分析, 並在每場比賽時測驗心跳率 (HR)、運動自覺量表 (RPE)和血乳酸濃度 (LA)做為生理反應的評 估指標。結果顯示, 羽球新、舊制比賽間引起心跳率峰值 $\left(\mathrm{HR}_{\text {peak }}\right)>\mathrm{RPE}$ 或血乳酸上升的反應並無統計差異。然而, 舊制比賽 時 $>90 \% \mathrm{HR}_{\text {peak }}$ 強度的比率 $(63 \%)$ 明顯比新制 $(54 \%$ ) 來得多。新制比賽的整場比賽完成時間 (PT : 29分鐘) 、淨比賽時間 (10分 鐘)、運動密度 $(0.57)$ 、休息時間 (18分鐘)、比賽時間效益 $(36 \%)$ 、每球來回完成次數 (203) 及發球次數 (35)都明顯比舊制 (例 如PT：42分鐘)縮短，但二種不同比賽間在揮拍次數、每球來回完成時間、擊球時間、擊球方式、擊球位置及每球最後一拍的擊 球方式均無統計差異。這些結果顯示, 新賽制規則改變會比舊賽制明顯縮短比賽時間, 但不同賽制間所引起的生理反應、擊球方 式及位置則不因規則改變而受到影響。此外, 舊賽制比新賽制出現較高心跳率分佈情形, 可歸因於舊制比賽之雙方選手有較多對 抗機會或較長比賽時間所造成的。

關鍵詞：羽球落地得分制，羽球發球得分制，羽毛球，心跳率峰值 $\left(\mathrm{HR}_{\text {peak }}\right)$ ，血乳酸濃度 $(\mathrm{LA})$ 。 


\section{Introduction}

Badminton is a fast and dynamic sport that requires a balance of physiological preparation and tactical exercise (Downey, 1982; Pearce, 2002). Generally, there are five disciplines within the sport of badminton: men's and women's singles, men's and women's doubles, and mixed doubles. Each discipline requires unique on-court preparation using specific drills based on the tactical characteristics pertaining to that discipline. For instance, singles training drills are based around patience, control, and stamina. In a match situation, players usually establish the rally for a winning shot only after trying out various kinds of shots and placements that allow for an effective smash or shot (Hong \& Tong, 2000).

In 2006, the scoring system in badminton was changed from the traditional 3 innings to 15 points (i.e., scoring-by-service) system (with the exception of women's singles, which used the 3 games to 11 points system), to the new 3 innings to 21 points (i.e., rally-point scoring) system for all disciplines. The goal of this new system was to shorten the playing time of badminton matches, making matches faster or more competitive, in an effort to increase the sport's popularity around the world (http:// www.internationalbaminton.org/statues.asp). To date, there has been only one previous study (Chen \& Chen, 2008) to compare the effects of the new and old systems on men's badminton singles using notational analysis. The authors reported that while playing time (PT; $13 \mathrm{~min}$ ), rest time (RT; $9 \mathrm{~min}$ ), stroke time (ST: $0.98 \mathrm{~s}$ ) and number of services (NOS; 33) under the new system were significantly smaller than under the old system (PT: 20 min, RT: 14 min, ST: 1.05 s, NOS: 47), the number of shots per rally under the new system (8.4) was greater than under the old system (7.5). Chen and Chen (2008) also postulated that the shorter playing time under the new system could possibly lead to changes in tactical strategy, such as shot selection. This, in turn, would result in greater physiological demand (i.e., exercise intensity) during the singles matches than was seen under the old scoring-by-service system. Since the aforementioned study (Chen \& Chen, 2008) did not include the physiological and shot selection parameters of badminton matches under the two systems, it is not known whether physiological demand and shot selection would be affected by the shorter playing time under the new system as compared to the old system.
Therefore, the purpose of this study was to test the hypothesis that the shorter playing time of the rally-point system could be related to the increased physiological demand or changes in shot selection in comparison to the scoring-by-service system. The information gathered as a result of this study will provide coaches and sports scientists with detailed information on the differences in physiological demand, shot selection and tactics between the rally-point and scoring-by-service systems. This, in turn, will assist them in preparing badminton players for competition under the new scoring system.

\section{Method}

\section{Participants and General Procedure}

Ten males athletes who had participated in badminton training for at least 10 years prior to this study, participated in this study that had been approved by the Institutional Ethics Committee. They provided written informed consent using a university-approved document in conformity with the Declaration of Helsinki before participation. Their mean $( \pm \mathrm{SD})$ age, stature, and body mass were $20.6 \pm 1.4 \mathrm{yrs}, 177.4 \pm 4.9 \mathrm{~cm}$, and $71.2 \pm 6.8 \mathrm{~kg}$, respectively. All athletes were right-handed players. All athletes were first-level national players in Taiwan, and all were training and competing regularly in national level matches at the time of the study. All players were requested to refrain from performing any unaccustomed exercise or vigorous physical activity, and from taking any anti-inflammatory agents or nutritional supplements during the experimental period.

Three to five days before the first match, all players were asked to familiarize themselves with the old scoring system. Ten matches were completed in this study. Each player played two matches against the same opponent using the lottery method. One match consisted of 3 innings to 15 points (i.e., scoring-by-service system), and the other consisted of 3 innings to 21 points (i.e., rally-point system). Among the ten matches, three were played first with the rally-point system followed at least two days later by the scoring-by-service system. The other two were played first with the scoring-by-service system followed by the rally-point system at least two days later. Two days were given between the two matches in order to allow players to fully recover from the first match. 


\section{Scoring-by-service Scoring (3 x 15) System}

The traditional $3 \times 15$ scoring system was used until the end of the year 2005. In this study, subjects were instructed before each match to play with as much effort as possible, simulating a competition environment. In order to encourage subjects to play their best during matches, we gave $\$ 1500$ NTD to the winner of each match, and \$500 NTD to the loser. After an individual warm-up of about 10 minutes, three innings of 15 points were played regardless of the match status. That is, even if the score after two innings was 2 to 0 , a third inning was still played. A $90 \mathrm{~s}$ rest period was given between the first and second innings, followed by a 5-minute break between the second and third innings, in conformity with International Badminton Federation (IBF) regulations (http://www.internationalbaminton.org/statues.asp), in order to further simulate competition conditions. During the breaks between innings, water intake was allowed based on the laws of badminton.

\section{Rally-point Scoring (3 x 21) System}

To simulate competition conditions, the same instructions and rewards were given to subjects when playing under the new system. That is, they were told to play with as much effort as possible, and to play three innings regardless of match status. Based on IBF regulations for the new system, players took a 2-minute break between each of the 3 innings. Water intake was also allowed during these breaks, based on the laws of badminton.

\section{Physiological Measurements}

For matches played under both the new and old systems, players' heart rates (HR) were measured using HR monitors (Polar S610, Polar Electro Oy, Kempele, Finland) for the duration of the match. HR analysis included comparison of peak $\mathrm{HR}\left(\mathrm{HR}_{\text {peak }}\right)$ experienced by the players, and comparison of the amount of time spent in HR zones of $60-69 \%, 70-79 \%, 80-89 \%$, and greater than $90 \%$ of the player's $\mathrm{HR}_{\text {peak }}$ in both systems (Pearce, 2002). Ratings of perceived exertion (RPE) were assessed immediately after each inning using a Borg scale (Borg, 1970). Blood lactate (LA) concentration was measured with a portable Lactate-Pro analyzer (Lactate $\mathrm{Pro}^{\mathrm{TM}}$, Tester Meter, Arkray Inc., Kyoto, Japan) immediately after each inning using blood samples from the fingertip. It should be also noted that the resting HR, RPE, and LA concentrations of all players were measured before each match, in order to make sure these measures were within the normal range for each player.

\section{Notational Analysis}

Since temporal structure, shot selection and positions, or shot methods of the last shot have often been used in previous studies as indicators of notational analysis for evaluating badminton (Liddle, Murphy, \& Bleakley, 1996; Hong \& Tong, 2000; Pearce, 2002; Faude, et al., 2007; Chen \& Chen, 2008), notational analysis was also used to classify the type and frequencies of shots played in both systems in this study. Matches were recorded using a video camera (GR-DVL9800U, JVC Co. Kanagawa, Japan) with a wide-angle lens, placed $2 \mathrm{~m}$ away at the rear of the court at an angle of $45^{\circ}$. Analyses of the videotaped matches were performed using the notational system described by Hong and Tong (2000), Pearce (2002), and Chen and Chen (2008). Briefly, for each player, each shot was identified and categorized as described in temporal structure, shot selection and positions, and shot methods of the last shot in the next section.

It should be noted that all notations were analyzed by the same investigator to minimize errors in reliability. These procedures were according to those used previously by Hong and Tong (2000) and Chen and Chen (2008). The intra-rater analysis of the reliability coefficient for all variables was $\geq .98$ between observations, which is considered to be acceptable.

\section{Temporal Structure}

Number of shots per rally. The total number of times the shuttle was hit by both players from the serve until it hit the ground.

Rally time. The time elapsed from the serve until the shuttle hit the ground.

Stroke time. Rally time divided by the number of shots per rally.

Match duration. In each match, the time elapsed from the first serve until the shuttle hit the ground for the last time, not including the rest periods between the innings.

Number of serves. The combined number of serves by both players in each match. 
Rest time. In each match, the time elapsed from the time the shuttle hit the ground until the racquet hit the shuttle for the following serve.

Work density. Rally time divided by rest time.

Effective playing time. Rally time divided by rally + rest time expressed in percent.

Shot frequency. Number of shots per rally time in shots per second.

\section{Shot Selection}

Categories of shots played during the matches were adopted from previous studies (Pearce, 2002; Cabello Manrique \& González-Badillo, 2003). Each category was defined as follows:

Serve. Service shots were further classified into: 1) Short: Shuttle is served low over the net, landing near the front of the service line; and 2) Deep: Shuttle is served high, and hit overhead deep to the back of the court (Pearce, 2002). It should be noted that a service shot was considered "deep" when the shuttlecock flew to the back of the court (i.e., the area between the long service and back boundary lines), regardless of whether the shuttle was hit using a forehand or a backhand stroke.

Rally shot. Rally shots in this study were further sub-categorized as follows: 1) Drop: Slower shot played overhead but downward to the front of the court; 2) Smash: Aggressive shot played overhead in a downward trajectory; 3) Net: Precise shot played near the net; 4) Push: Shuttle is played in either mid-court or frontcourt with a flat trajectory (defense and drive are also considered push shots if they have flat trajectories); and 5) Lift: Underarm shot played high and deep to the back of the court from the mid-court or frontcourt position (Pearce, 2002).

\section{Shot Positions}

The method of identifying shot positions was the same method used by Hong and Tong (2000) to identify the moves of players during matches. That is, moves were identified according to which of the following six areas they were played from: right or left forecourt, right or left mid-court, or right or left rear court. Further details concerning the shot positions procedures can be found in a previous related study (Hong \& Tong 2000).

\section{Shot Methods of the Last Shot}

Categories used to record the last shot per rally were the same as those used to record other shots, that is: clear, smash, drop, drive, lift, net, and push.

Categories of winning and losing shots were adopted from previous studies (Pearce, 2002; Cabello Manrique \& González-Badillo, 2003), and each category was defined as follows:

Winner shot. A shot that wins a rally by good placement outright.

Forced winner. A shot that wins the rally by luck.

Forced error. A rally lost by the player due to pressured or aggressive play by the opponent.

Unforced error. A rally lost by the player due to an inaccurate mistake without undue pressure applied by the opponent.

\section{Statistical Analysis}

Each physiological (i.e., $\mathrm{HR}_{\text {peak }},>90 \% \mathrm{HR}_{\text {peak }}$, $80-89 \% \mathrm{HR}_{\text {peak }}, \quad 70-79 \% \mathrm{HR}_{\text {peak }}, \quad 60-69 \% \mathrm{HR}_{\text {peak }},<59 \% \mathrm{HR}_{\text {peak }}$, LA, RPE) and notational variable (i.e., temporal structure: playing time, rally time, etc; shot selection: clear, drop, etc; shot positions: right- and left-forecourt, mid court and rear court; shot methods in the last shot: clear, drop, etc) of the matches between the new and old systems was compared using a paired test. Each physiological and notational variable during the first, second and third innings of the matches in the new and old systems, respectively, was analyzed using a one-way repeated measures analysis of variance (ANOVA). Physiological and notational variables during the first, second and third innings of the matches between the new and old systems were analyzed using a two-way ANOVA. When a significant effect (formats, innings or formats $\mathrm{x}$ innings) was evident, a Bonferroni post hoc test was performed to check the difference at each time point. Statistical significance was accepted at $\mathrm{p}<.05$. Data were presented as mean $\pm \mathrm{SD}$, unless otherwise stated. 


\section{Results}

\section{Physiological Measurements}

Table 1 shows differences in LA, RPE and $\mathrm{HR}_{\text {peak }}$ during matches played using the new vs. old scoring systems. LA was moderate $(p<.05)$ and showed no significant difference between the two systems, ranging from 4.2 to $5.1 \mu \mathrm{g} \cdot \mathrm{L}^{-1}\left(4.6 \pm 0.4 \mu \mathrm{g} \cdot \mathrm{L}^{-1}\right)$ in matches played using the new system, with similar results ( $p>$ .05) observed during matches played using the old system $\left(4.8-5.8 \mu \mathrm{g} \cdot \mathrm{L}^{-1} ; 5.3 \pm 0.7 \mu \mathrm{g} \cdot \mathrm{L}^{-1}\right)$. A similar result was also found for $\operatorname{RPE}(\mathrm{p}>.05$; new: $13.1 \pm 0.6$, old: $13.6 \pm 0.6)$. Moreover, the players' on-court $\mathrm{HR}_{\text {peak }}$ values showed no significant difference $(\mathrm{p}>.05)$ between the new $(180 \pm 2$ beats $/ \mathrm{min})$ and old $(183 \pm 3$ beats $/ \mathrm{min})$ scoring systems (Table 1). However, the amount of time spent at $>90 \% \mathrm{HR}_{\text {peak }}$ under the old system $(63 \% \pm 4 \%$ of total match time) was significantly greater $(p<.05)$ than under the new system $(54 \% \pm 3 \%$ of total match time), although there was no significant difference $(p>.05)$ between the systems for the amount of time spent in other $\% \mathrm{HR}_{\text {peak }}$ zones (Figure 1).

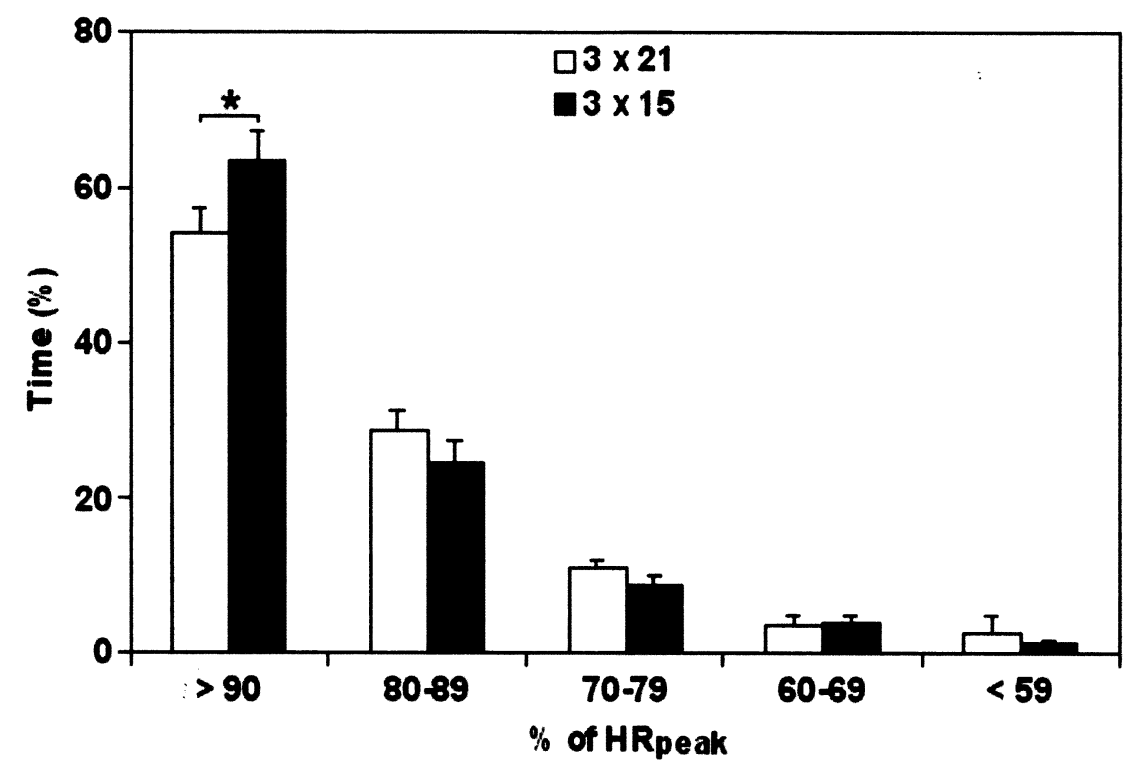

Figure 1. Normalized percentage of match time spent at different $\%$ of $H R_{\text {peak }}$ (mean $\pm S D$ ) between the new $(3 x \quad 21)$ and old $(3 x \quad 15)$ systems.

* indicates a significant difference $(p<.05)$ between the systems

Table 1. Changes in peak heart rate $\left(\mathrm{HR}_{\text {peak }}\right.$; mean $\left.\pm \mathrm{SD}\right)$, blood lactate $(\mathrm{LA})$, and ratings of perceived exertion (RPE) between the new $(3 \times 21)$ and old $(3 \times 15)$ scoring systems of badminton singles matches.

\begin{tabular}{llcl}
\hline Dependent variables & New & Old & p-value \\
\hline Blood lactate $(\mu \mathrm{M} / \mathrm{L})$ & $5.1 \pm 1.5$ & $5.8 \pm 3.0$ & .514 \\
$1^{\text {st }}$ inning & $4.5 \pm 1.9$ & $5.3 \pm 1.9$ & .290 \\
$2^{\text {nd }}$ inning & $4.2 \pm 1.4$ & $4.8 \pm 2.2$ & .278 \\
$3^{\text {rd }}$ inning & $4.6 \pm 0.4$ & $5.3 \pm 0.7$ & .241 \\
Overall average & & & \\
Ratings of perceived exertion & $13.0 \pm 1.6$ & $13.1 \pm 1.8$ & .790 \\
$1^{\text {st }}$ inning & $13.0 \pm 2.1$ & $13.8 \pm 1.6$ & .101 \\
$2^{\text {nd }}$ inning & $13.5 \pm 2.0$ & $14.0 \pm 2.4^{*}$ & .307 \\
$3^{\text {rd }}$ inning & $13.1 \pm 0.6$ & $13.6 \pm 0.6$ & .243 \\
Overall average & & & \\
Peak heart rate (beats/min) & $172.7 \pm 6.4$ & $178.5 \pm 9.6$ & .145 \\
$1^{\text {st }}$ inning & $181.3 \pm 7.2^{*}$ & $183.9 \pm 8.8^{*}$ & .419 \\
$2^{\text {nd }}$ inning & $182.8 \pm 6.5^{*}$ & $185.4 \pm 8.4^{*}$ & .416 \\
$3^{\text {rd }}$ inning & $178.9 \pm 1.8$ & $182.6 \pm 2.7$ & .225 \\
Overall average &
\end{tabular}

* indicates a significant difference compared to the 1 st inning $(\mathrm{p}<.05)$. 


\section{Temporal Structure}

Tables 2 and 3 present a comparison of temporal structure in matches played using the new vs. old scoring systems. A significant $(\mathrm{p}<.05)$ decrease in total playing time (PT: $29 \pm 3 \mathrm{~min}$ ), work time (WT: $10.4 \pm 1.3$ min), work density (WD: $0.57 \pm 0.01$ ), rest time (RT: $18.1 \pm 1.8 \mathrm{~min}$ ), effective playing time (EPT: $36.4 \pm 2.4 \%$ ), number of rallies $(203 \pm 40)$ and serves $(34.5 \pm 2.3)$ was noted in matches played under the new compared to the old scoring system (e.g. PT: $42 \pm 13$ min, WT: 15.9 $\pm 2.3 \mathrm{~min}$, WD: $0.63 \pm 0.32$, RT: $26.4 \pm 9.6 \mathrm{~min}$, EPT: $38.5 \pm 3.5 \%$, number of rallies: $306 \pm 99$, number of serves: $50.6 \pm 6.6)$. No significant differences $(p>.05)$ were noted between the two systems for rally time, stroke time, and number of shots per rally (Table 3).

Table 2. Differences in match playing time (PT), work time (WT), rest time (RT), work density (WD), effective playing time (EPT), and number of rallies and shots played between the new ( $3 \times 21)$ and old ( $3 \times 15)$ scoring systems of badminton singles matches (mean \pm SD).

\begin{tabular}{llll}
\hline Dependent variables & New & Old & p-values \\
\hline Playing time (min) & $9.3 \pm 1.1$ & $12.7 \pm 3.0$ & .001 \\
$1^{\text {st }}$ inning & $9.3 \pm 1.7$ & $14.4 \pm 3.9$ & .002 \\
$2^{\text {nd }}$ inning & $9.9 \pm 1.9$ & $15.2 \pm 4.4$ & .048 \\
$3^{\text {rd }}$ inning & $9.5 \pm 1.6$ & $14.1 \pm 4.1$ & .005 \\
Overall average & & & \\
Work time (min) & $3.5 \pm 0.4$ & $5.2 \pm 1.2$ & .000 \\
$1^{\text {st }}$ inning & $3.4 \pm 0.9$ & $5.6 \pm 1.4$ & .000 \\
$2^{\text {nd }}$ inning & $3.5 \pm 0.7$ & $5.2 \pm 2.3$ & .037 \\
$3^{\text {rd }}$ inning & $3.5 \pm 0.7$ & $5.3 \pm 1.6$ & .001 \\
Overall average & & & \\
Rest time (min) & $5.8 \pm 0.8$ & $7.5 \pm 2.0$ & .003 \\
$1^{\text {st }}$ inning & $5.9 \pm 0.9$ & $8.8 \pm 2.7$ & .008 \\
$2^{\text {nd }}$ inning & $6.4 \pm 1.2$ & $10.0 \pm 3.3$ & .076 \\
$3^{\text {rd }}$ inning & $6.0 \pm 0.9$ & $8.8 \pm 2.8$ & .016 \\
Overall average & & & \\
Work density $^{\text {st }}$ inning & $0.61 \pm 0.06$ & $0.70 \pm 0.10$ & .007 \\
$2^{\text {nd }}$ inning & $0.57 \pm 0.07$ & $0.65 \pm 0.11$ & .035 \\
$3^{\text {rd }}$ inning & $0.55 \pm 0.05$ & $0.55 \pm 0.12^{* \dagger}$ & .956 \\
Overall average & $0.57 \pm 0.06$ & $0.63 \pm 0.11$ & .041 \\
EPT $(\%)$ & & & \\
$1^{\text {st }}$ inning & $37.6 \pm 2.3$ & $41.1 \pm 3.4$ & .005 \\
$2^{\text {nd }}$ inning & $36.1 \pm 2.8$ & $39.0 \pm 4.1$ & .024 \\
$3^{\text {rd }}$ inning & $35.4 \pm 2.3$ & $35.2 \pm 3.0^{*+}$ & .891 \\
Overall average & $36.4 \pm 2.4$ & $38.5 \pm 3.5$ & .046 \\
\hline
\end{tabular}

* indicates a significant difference from the $1^{\text {st }}$ inning $(\mathrm{p}<.05)$;

indicates a significant difference from the $2^{\text {nd }}$ inning $(\mathrm{p}<.05)$. 
Table 3. Differences in number of serves, shots per rally, rally time, and stroke time of shots played between the new $(3 \times 21)$ and old $(3 \times 15)$ scoring systems of badminton singles matches (mean $\pm \mathrm{SD})$.

\begin{tabular}{llll}
\hline Dependent variables & New & Old & p-values \\
\hline No. of serves & $34.7 \pm 3.3$ & $50.2 \pm 5.9$ & .001 \\
$1^{\text {st }}$ inning & $34.2 \pm 3.9$ & $52.6 \pm 7.6$ & .001 \\
$2^{\text {nd }}$ inning & $34.6 \pm 5.4$ & $48.9 \pm 5.6$ & .01 \\
$3^{\text {rd }}$ inning & $34.5 \pm 2.3$ & $50.6 \pm 6.6$ & .001 \\
Overall average & & & \\
No. of shots per rally & $5.8 \pm 0.7$ & $5.8 \pm 1.1$ & .99 \\
$1^{\text {st }}$ inning & $5.9 \pm 1.1$ & $6.1 \pm 1.2$ & .068 \\
$2^{\text {nd }}$ inning & $6.0 \pm 0.7$ & $6.0 \pm 1.3$ & .088 \\
$3^{\text {rd }}$ inning & $5.9 \pm 0.8$ & $6.0 \pm 1.2$ & .79 \\
Overall average & & & \\
Rally time (s) & $6.1 \pm 0.7$ & $6.2 \pm 0.9$ & .67 \\
$1^{\text {st }}$ inning & $5.9 \pm 1.1$ & $6.4 \pm 1.1$ & .37 \\
$2^{\text {nd }}$ inning & $6.1 \pm 0.8$ & $6.1 \pm 1.5$ & .90 \\
$3^{\text {rd } \text { inning }}$ & $6.0 \pm 0.6$ & $6.2 \pm 1.0$ & .47 \\
Overall average & & & \\
Stroke time (s) & $1.05 \pm 0.10$ & $1.08 \pm 0.13$ & .38 \\
$1^{\text {st }}$ inning & $1.01 \pm 0.09$ & $1.05 \pm 0.07$ & .30 \\
$2^{\text {nd }}$ inning & $1.02 \pm 0.11$ & $1.02 \pm 0.08$ & .98 \\
$3^{\text {rd } \text { inning }}$ Overall average & $1.03 \pm 0.07$ & $1.05 \pm 0.08$ & .47 \\
\hline
\end{tabular}

Figure 2 shows the rally and rest time interval distribution during badminton matches played under the new and old systems. A total of 1,040 and 1,532 rallies (not including service) were played in the five matches under the new and old systems, respectively. The percentage of rallies lasting less than $9 \mathrm{~s}$ were $84.6 \%$ and $82.2 \%$ for the new and old systems, respectively, while the percentage of rallies lasting longer than $10 \mathrm{~s}$ were $15.4 \%$ and $\mathbf{1 7 . 8 \%}$, respectively (Figure 2). However, rest time frequently lasted between 4 and $12 \mathrm{~s}$ for both the new (88.0\%) and old (80.4\%) systems, respectively.

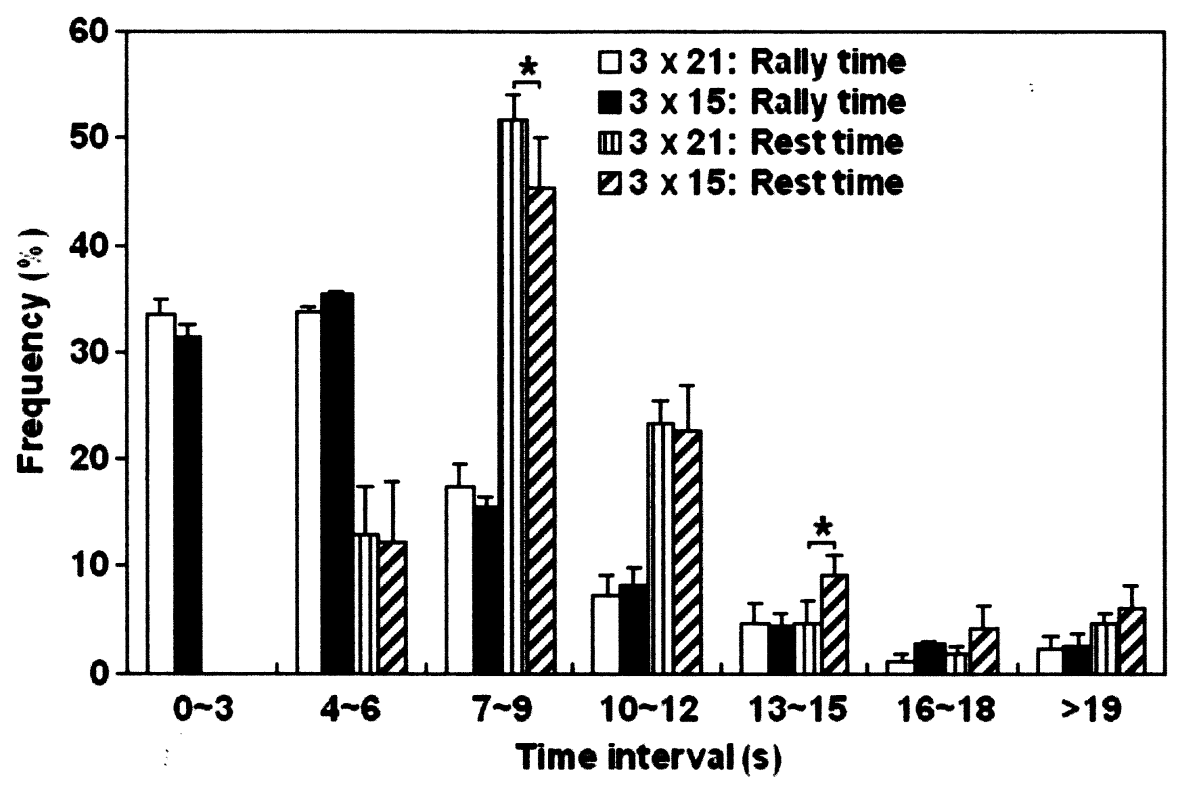

Figure 2. Frequency distribution of rally and rest time intervals during badminton matches between the new $\left(3 x\right.$ 21) and old $\left(\begin{array}{llll}3 & x & 15\end{array}\right)$ systems.

* indicates a significant difference $(p<.05)$ between the systems. 
Shot Selection and Positions, and Shot Methods of the Last Shot

Figure $3 \mathrm{a}$ presents the frequency distribution of all rally shots analyzed (not including service). Of the 1,040 rally shots played in matches scored using the new system and 1,532 rally shots played in matches scored using the old system, the net and lift were the most frequently played. Under the new scoring system, the net and lift constituted $43 \pm 4 \%$ and $35 \pm 3 \%$ of all shots, respectively, while the old system demonstrated a $33 \pm 5 \%$ and $25 \pm 4 \%$ for net and lift distribution, respectively. Comparison of the net and lift shots between the two systems indicated that both were played more frequently $(\mathrm{p}<.05)$ under the new system than under the old system.
In contrast, a comparison of other types of shots (i.e., clear, smash, drop and push) showed no significant difference $(p>.05)$ between the new and old systems. The smash was used only slightly more frequently $(\mathrm{p}>$ $.05)$ under the new $(17 \pm 3 \%)$ than under the old system $(12 \pm 3 \%)$. The situation was similar for the clear, push, and drop shots, with the clear accounting for $15 \%$ vs. $12 \%$, the push accounting for $7 \%$ vs. $6 \%$, and the drop accounting for $13 \%$ vs. $13 \%$ under the new and old systems, respectively (Figure 3a). This was also the case for the frequency distribution of shot areas (fore-, mid, and rear-left and -right) during the matches ( $p>.05$; Figure $3 \mathrm{~b}$ ), and the frequency distribution of shot methods of the last shot per rally during the matches between the systems $(\mathrm{p}>.05$; Figure $3 \mathrm{c})$.
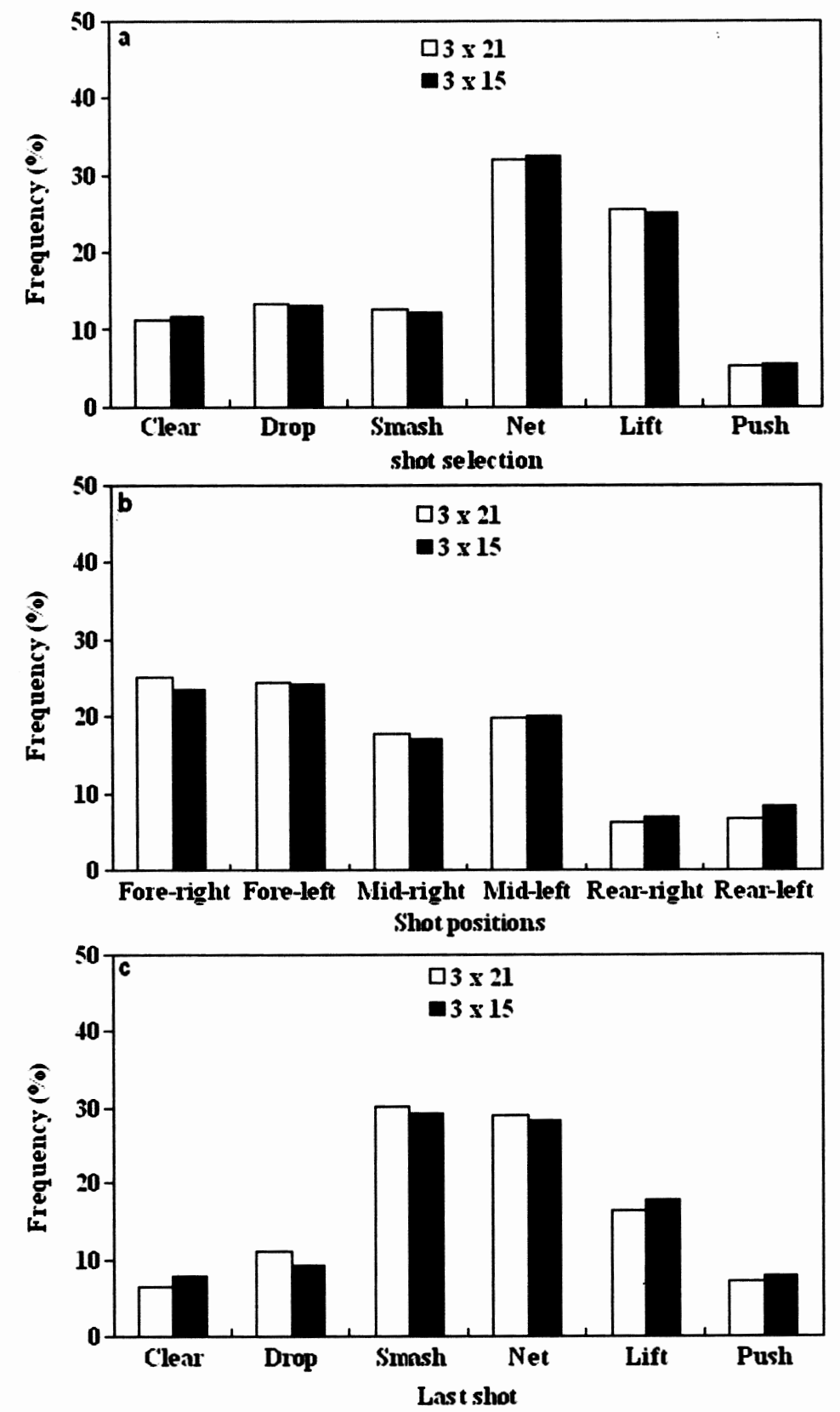

Figure 3. Frequency distribution of shot selection (a), shot positions (b), and shot methods of the last shot (c; not including services; mean $\pm S D)$ between the new $(3 x$ 21) and old $\left(\begin{array}{lll}3 & x & 15\end{array}\right)$ systems. No significant difference $(p>.05)$ between the systems was observed for shot selection, shot position, or shot methods of the last shot. 
In Figure 4a, which shows the frequency distribution of the three overhead shots (clear, drop and smash) during the matches, we see that the clear, drop and smash were all predominant shots under both the new and old systems $(\mathrm{p}>.05)$. For example, the smash was used consistently throughout all matches played - ranging from $4 \%$ in the first inning to $5 \%$ in the third inning regardless of which scoring system was used.
Figure $4 \mathrm{~b}$ shows the frequency distribution of short and deep serves during the course of the matches. Although in both systems, the short serve was found to be preferred over the deep serve $(p<.05)$, the frequency distribution of short serves in the new system was greater $(\mathrm{p}$ $<$.05) than the old system. That is, of the 1,518 serves in the old system, $68 \%$ were short serves; in the new system, $78 \%$ were short serves.

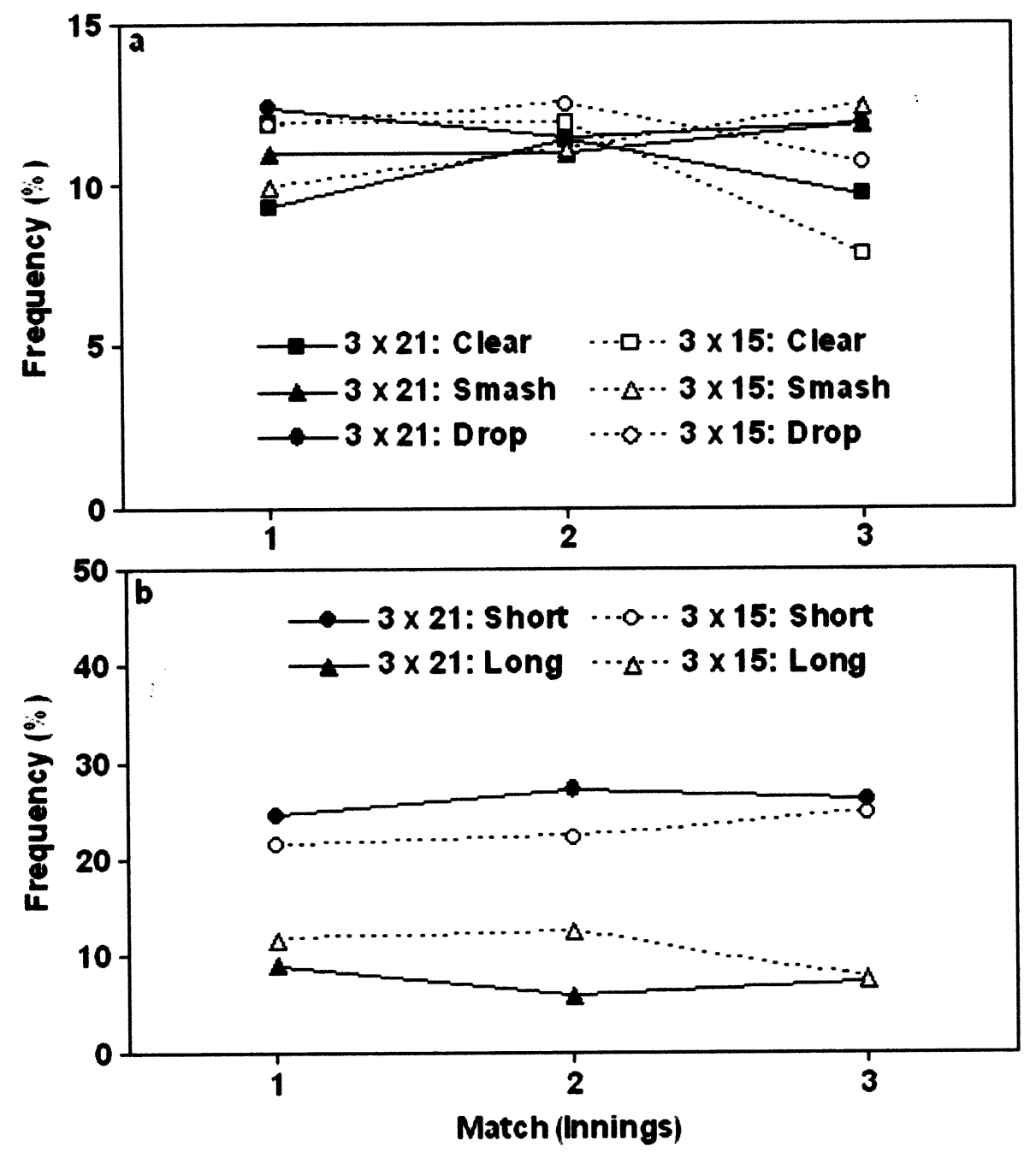

Figure 4. Frequency distribution of the three overhead shots (clear, drop and smash; a), and frequency distribution of short and deep serves $(b)$ during the course of the match $(p>.05) . *$ indicates a significant difference $(p<.05)$ between the systems. 
Table 4 shows frequency distribution of the categories of winning and losing shots between the two scoring systems. It was found that the proportions of winners and errors played by each player were similar ( $>$ >05; Table 4), regardless of which system was used. Moreover, successful players seemed to make fewer errors (both forced and unforced) than losing players, under both systems.

Table 4. Differences in the frequency distribution of the categories of winning and losing shots between the new $(3 \times 21)$ and old $(3 \times 15)$ scoring systems of badminton singles matches (mean \pm SD). No significant difference $(p>.05)$ between the systems was observed.

\begin{tabular}{|c|c|c|c|c|}
\hline & $\begin{array}{l}\text { New } \\
\text { Winner }(\%)\end{array}$ & Loser $(\%)$ & $\begin{array}{l}\text { Old } \\
\text { Winner (\%) }\end{array}$ & Loser $(\%)$ \\
\hline Winner & 33 & 20 & 36 & 22 \\
\hline Forced winner & 2 & 1 & 1 & 1 \\
\hline Unforced error & 55 & 68 & 50 & 62 \\
\hline Forced error & 10 & 11 & 13 & 15 \\
\hline
\end{tabular}

\section{Discussion}

This study was to test the hypothesis that the introduction of the $3 \times 21$ (new) scoring system by the IBF would make badminton matches shorter, faster or more physiologically demanding than the $3 \times 15$ (old) system, and would affect shot selection during the matches. Although the results of this study confirmed that the playing time, work time, rest time, effective playing time, number of rallies and serves, and work density of matches played under the new system were significantly smaller than under the old system (Tables $2 \& 3$ ), the new and old systems resulted in similar physiological responses (Table 1), frequency distribution of shot selection (Figure $3 a$ ) and positions during the matches (Figure 3b), as well a similar frequency distribution of shot methods of the last shot per rally (Figure 3c). These results did not support our hypothesis that the shorter playing time under the new system would result in faster matches, greater physiological demand, or affected frequency distribution of shot selections during the matches compared to the old system.

Physiological variables such as HR, LA and RPE have frequently been used as indicators of exercise intensity, and have been used to determine the energy requirements of play during the course of a badminton match (Cabello Manrique \& González-Badillo, 2003; Docherty, 1982; Downey, 1982; Faccini \& Monte, 1996; Majumdar et al., 1997). In this study, LA $(\sim 5 \mu \mathrm{M} /$ L) and RPE ( 14) did significantly increase during the course of the matches without significant difference between the systems, and the players were working at similar HR intensities ( $91 \%$ of $\mathrm{HR}_{\text {peak }}$ ) during the course of the matches in both systems (Table 1). These results are similar to the findings of previous studies (Cabello Manrique \& González-Badillo, 2003; Faude et al., 2007; Ghosh, Goswami, \& Ahuja, 2003; Majumdar et al., 1997; Pearce, 2002). For example, Cabello Manrique and González-Badillo (2003) and Ghosh et al. (2003) found that average $\mathrm{HR}$ during the match remained at around $90 \% \mathrm{HR}_{\text {peak }}$ under the old system, while LA increased by about $4 \mu \mathrm{M} / \mathrm{L}$. Faude et al. (2007) observed similar results for $\mathrm{HR}\left(83 \% \mathrm{HR}_{\text {peak }}\right)$, but a lower LA increase $(\sim 2 \mu \mathrm{M} / \mathrm{L})$ in matches played under the new system. The discrepancy of LA between the present study and that of Faude et al. may be explained by differences in the laws of badminton and study-design, as well as in the fitness, training levels and ranking position of the players. In the study of Faude et al., four international male players ranked between 49 and 164 played a match of two 15min innings with 2 min of rest in between, while in our study, ten of Taiwan's first-level male players played a match of 3 innings with 2 min rest in between. It is also possible that the low LA but high HR response during the match is related to the fact that in the Faude et al. (2007) study, each player wore a gas mask and a portable metabolic system (lightweight ambulatory metabolic device) during the match. This led to a slight but unavoidable decrease in exercise intensity, and consequently, in the glycolytic flux rate. Taken together, 
the finding that HR, LA and RPE change significantly during the match (Table 1) supports the hypothesis that repetitive efforts of intermittent nature and great intensity are continuously performed throughout the match (Faude et al., 2007; Chen \& Chen, 2008). Alternatively, it may suggest that the short and highly intense nature of both scoring systems may rely heavily on the phosphate creatine system, with remarkable contribution from the aerobic system.

When the frequency distribution of the various HR zones was further analyzed, we found that for zones less than $90 \% \mathrm{HR}_{\text {peak, }}$ there was no significant difference between the systems (Figure 1). However, the frequency distribution of $>90 \% \mathrm{HR}_{\text {peak }}$ was greater for the old system (63 $\pm 4 \%)$ than for the new system $(54 \pm 3 \%)$. This may be explained by the differences in the laws of badminton between the two systems. That is, the greater proportion of $>90 \% \mathrm{HR}_{\text {peak }}$ for the old system may be attributed to the greater duration of competition, and/or to the fact that players compete more intensely for the right to serve under this system (Chen \& Chen, 2008). Pearce (2002) also postulated that the old $(3 \times 15)$ system allowed greater tolerance for error, as there were many chances to regain the advantage; however in the new (3 $x$ 21) system, incurring even a small number of errors may be the difference between winning and losing. Moreover, this result is likely to be related to total playing time, as players had to work for a longer period of time under the old system $(42 \pm 10 \mathrm{~min})$ than under the new system (29 \pm 3 min; Table 2). Therefore, the results of our HR zone analysis in this study may provide valuable information for coaches and sports scientists to use when evaluating the performance of badminton players on the court.

It is well established that a winning strategy under the old scoring system is based around patience, control, stamina, and using a succession of shots to open up an area of the opponent's court for attack (Hong \& Tong, 2000). It has also been reported that the old system is based around effectively clearing the court and playing the drop shot to force a weak return, thus creating the opportunity to play a winning shot such as the smash (Downey, 1982; Hong \& Tong, 2000; Pearce, 2002). In addition, as matches under the old system can last more than an hour, and in some cases over 90 minutes (Ryan, 2001; Cabello Manrique \& González-Badillo, 2003), the deep, clear and drop shots are the preferred tactical shots against repeated smashing (Hong \& Tong, 2000; Pearce,
2002). However, results of the current study indicate that the frequency distribution of drop, smash, and clear shots is similar under both the old and new systems (Figure 3a). This finding is inconsistent with those of two previous studies (Blomqvist, Luthanen, \& Laakso, 1998; Pearce, 2002), which found that the clear and drop shots were the first and second most used (return) shots, while the smash was ranked about fourth to sixth. This discrepancy may be caused by differences in the analysis of shot selection, as well as in the ranking position of the players between the aforementioned and present studies (i.e., both of the aforementioned studies used notational analysis, and both adult and junior male players as subjects). Furthermore, the present study found that blood lactate slightly diminished and the frequency of smash shots increased as the matches progressed, without significant difference among the innings of each system (Table 1, Figure 4a). This may indicate either a tactical option to save as much energy as possible, or fatigue.

In this study, players preferred to use a short serve rather than the high serve in both systems, and the new system had a greater frequency distribution of short serves than the old system (Figure 4b). This finding is consistent with the results of a previous study (Pearce, 2002). It has been shown that the use of the short serve eliminates the chance for the opponent to make an attacking return such as a smash or drop shot, and this allows the server to be less defensive than when serving high (Hong \& Tong, 2000; Pearce, 2002). It appears that players may prefer to serve short and use the high serve as an alternative, with the purpose of gaining the initiative in the rally as early as possible (Pearce, 2002). Moreover, given the similarities in physiological response (Table 1), shot selection and positions (Figure $3 \mathrm{a}$ and $3 \mathrm{~b}$ ), and shot methods of the last shot per rally (Figure 3c) between the systems, this may suggest that the greater frequency of short serves in the new system does not necessarily indicate that it is more competitive and/or faster than the old system.

A recent study (Chen \& Chen, 2008) postulated that players may become more conservative, and aim to make fewer errors while playing under the old system compared to the new system. As shown in Table 4, the successful player made fewer forced or unforced errors under both systems, without significant differences between the systems. This finding is also similar to the results of Hong and Tong (2000), Pearce (2002), and Cabello Manrique and González-Badillo (2003), in which success 
was also related to limiting the number of unforced errors. Cabello Manrique \& González-Badillo (2003) suggested that the number of unforced errors affects the final result, and could be used to predict the outcome of the match as well as a player's performance level.

In conclusion, the results of this study showed that playing time, work time, work density, rest time, effective playing time, and number of shots and serves were significantly lower under the new system compared to the old system, without significant difference for the physiological and notational parameters between the systems. However, a greater proportion of higher than $90 \% \mathrm{HR}_{\text {peak }}$ intensities was observed under the old system. This may be attributed to a greater duration and/or degree of competition (i.e., players compete more intensely for the right to serve) under the old system than under the new system.

\section{References}

Blomqvist, M., Luthanen, P., \& Laakso, L. (1998). Validation of notational analysis system in badminton. Journal of Human Movement Studies, 35, 137-150.

Borg, G. (1970). Perceived exertion as an indicator of somatic stress. Scandinavian Journal of Rehabilitation Medicine, 2, 92-98.

Cabello Manrique, D., \& González-Badillo, J. J. (2003). Analysis of the characteristics of competitive badminton. British Journal of Sports Medicine, 37, 62-66.

Chen, H. L., \& Chen, T. C. (2008). Temporal structure comparison of the new and conventional scoring system for man's badminton singles in Taiwan. Journal of Exercise Science \& Fitness, 6, 34-43.

Docherty, D. (1982). A comparison of heart rate responses in racquet games. British Journal of Sports Medicine, 16, $96-100$.

Downey, J. (1982). Winning badminton singles. E. P. Publications, London.

Faccini, P., \& Monte, A. D. (1996). Physiologic demands of badminton match play. American Journal of Sports Medicine, 24, 64-66.
Faude, O., Meyer, T., Rosenberger, F., Fries, M., Huber, G., \& Kindermann, W. (2007). Physiological characteristics of badminton match play. European Journal of Applied Physiology, 100, 479-485.

Ghosh, A. K., Goswami, A., \& Ahuja, A. (2003). Evaluation of a sports specific training programme in badminton players. India Journal of Medical Research, 98, 232.

Hong, Y., \& Tong, Y. M. (2000). The playing pattern of the world's top single badminton players in competition: a notation analysis. Journal of Human Movement Studies, 38, 185-200.

Liddle, S. D., Murphy, M. H., \& Bleakley, W. (1996). A comparison of the physiological demands of singles and doubles badminton: a heart rate and time/motion analysis. Journal of Human Movement Studies, 30, $159-176$

Majumdar, P., Khanna, G. L., Malik, V., Sachdeva, S., Arif, M. D., \& Mandal, M. (1997). Physiological analysis to quantify training load in badminton. British Journal of Sports Medicine, 31, 342-345.

Pearce, A. J. (2002). A physiological and notational comparison of the conventional and new scoring systems in badminton. Journal of Human Movement Studies, 43, 49-67.

Ryan, A. (2001). Malaysia and "5 x 7" get off to flying start. Badminton Vision August 7.

\section{Author Note}

We would like to thank Miss Zi-Ling Hwang and Mr. Ming-Ju Lin for their help in data collection for this study.

\section{Correspondence}

Trevor C. Chen

Department of Physical Education

National Chiayi University

85 Wenlong Village, Minsyong Township

Chiayi County 62103, TAIWAN

Tel: +886-5-2263411 ext. 1282

Fax: +886-5-2063082

E-mail: trevorchen@mail.ncyu.edu.tw 